\title{
Action Research with Children: Lessons from Tackling Disasters and Climate Change*
}

\author{
Thomas Tanner and Frances Seballos
}

\begin{abstract}
Recent research and practice from the fields of climate change adaptation and disaster management has created a shift from emphasis of children's vulnerability and need for protection towards their potential as agents of change before, during and after disaster events. This article examines lessons from action research into children's agency in disaster-prone communities of El Salvador and the Philippines. We describe some of the participatory risk management methods that were adapted for use with children, the centrality of ethics to our approach and the importance of working with a non-governmental organisation (NGO) partner that provides ongoing support in the study communities. The research design was led by external agents in order to cross-compare findings across locations and countries. However, we argue that by engaging children in a process of knowledge generation and analysis, the research broke down some of the assumed hierarchies between researcher and researched common to orthodox approaches.
\end{abstract}

\section{Children, climate change and disasters}

The links between children, climate change impacts and disaster events have most commonly been understood from the perspective of vulnerability, especially through psychosocial, nutrition, health and livelihoods impacts on children (Bunyavanich et al. 2003; Balaban 2006; del Ninno and Lindberg 2005; Waterson 2006). This approach emphasises the need for attention to child protection during and after disaster events (Lauten and Lietz 2008; Weissbecker et al. 2008).

In contrast, recent research and practice from the fields of climate change adaptation and disaster management has emphasised the potential of children to act as agents of change (Tanner 2010; Seballos and Tanner 2011). This change in narrative has been accompanied by calls for research that informs a child-centred approach to tackling the impacts of extreme events (Peek 2008; Tanner et al. 2009). This has included greater attention to disaster preparedness and climate change programmes in education and schools (Wisner 2006; Bangay and Blum 2010), but also acknowledges the unique risk perceptions and risk communication processes of children, and their capacity to act as agents of change before, during and after disaster events (see case studies in Peek 2008; Back et al. 2009; Tanner 2010).

Although children form a significant proportion in any community, children's voices are seldom heard, nor are their views taken into account in household and community decision-making. Recent research suggests that children have a unique perception of disaster risks, combining external information with their own experiences, and are able to communicate these perceptions to others to bring about changes in behaviour that can reduce risks and vulnerabilities (Tanner 2010). Child agency can alter their own risk behaviour at the household and community scale, but also mobilise adults and external policy actors to change wider determinants of risk and vulnerability (Tanner et al. 2009; Mitchell et al. 2008). The implication of such research is that greater resources should be channelled towards empowering children's agency, including enhanced efforts to incorporate children's perspectives, knowledge, and potential for action into community-driven development programmes. Involving children in research will be a crucial part of this effort, both in improving the overall quality and relevance of knowledge 
that informs policies and programmes, and empowering children to take actions that relate to their future lives.

In spite of this, children are often overlooked by research and practice at community level. We argue elsewhere that field-based research on community-based adaptation to climate change needs to engage with different sections of communities, including children (Tanner et al. 2009; Seballos and Tanner 2011). This article investigates the extent to which this gap may be filled through the development and promotion of appropriate action research approaches and tools. We present lessons from recent childfocused action research on disaster management in El Salvador and the Philippines, drawing out lessons for Participatory Action Research (PAR) approaches, and propose a normative framework for PAR in taking a child-centred approach to community-based climate change adaptation and disaster risk management.

\section{Why is PAR an appropriate approach for children and disasters issues?}

Our approach to PAR as discussed here is led broadly by the description of PAR as involving 'Researchers and participants working together to examine a problematic situation or action to change it for the better' (Kindon et al. 2007) and the contention that in undertaking research 'The point is to change the world, not only study it' (Maguire 2001). This implies combining aspects of participatory approaches that acknowledge the intellectual knowledge of the subjects of social research with the action research approach pioneered by Kurt Lewin centred on a belief that by examining their own realities, people organise themselves to improve their conditions (Chambers 2000; McIntyre 2008; McTaggart 1997). This is reinforced by a normative belief that by supporting communities to reflect on and examine their own practice through PAR 'Those who are currently poor and oppressed will progressively transform their environment by their own praxis. In this process others may play a catalytic or supportive role, but will not dominate' (Rahman 1993: 68). The action research process therefore involves cooperative enquiry to examine existing practice, reflect on and improve strategies, skills or techniques in order to improve.

PAR engagement with children has been spearheaded in particular by work in the health sector and its origins in education and learning (Minkler and Wallerstein 2003; Carr and Kemmis 1986). It has also been increasingly employed in a developing country context. PAR has been regarded as particularly appropriate as it is able to address key aspects of children and development, including taking responsibility, balancing participation with mediation and contesting spaces for children's agency

(Nieuwenhuys 1997). It also enables researchers to engage with multiple aspects of child participation, from analysis and interpretation to communication and mobilisation (Tanner 2010).

Although the most valuable understanding of the risks facing the lives of children in developing countries may lie with children themselves, there is a risk that exposing children to concepts and discussion around life-threatening issues through extractive research can create feelings of helplessness, denial and disempowerment. The existence of potentially negative impacts of undertaking PAR indicates the complex politics that underlie it and has provided a critique of the assumedly progressive nature of the approach (Harvey, Burns and Oswald, this IDS Bulletin; Ince 2008). However, our experience suggests that thoughtfully designed participatory action research can enable a two-way relationship between researchers and children that can minimise negative effects and contribute to building the capacity and agency of child participants.

Well-designed PAR with children is an inclusive process that allows children to be active coresearchers instead of passive research subjects. The research process becomes part of a learning cycle for both children and external researchers. Crucially, PAR enables children to undertake their own analysis of the local situation. In this way, rather than seeing climate change and disaster risks as something external, they can relate them to tangible issues that affect their own lives and communities. Rather than being driven by assessments from the physical sciences, the results often entail children relating hazards and factors driving vulnerability to their own experiences such as localised landslides, polluted watercourses, or dangerous roads (Tanner $e$ al. 2009). Participatory research methods can facilitate such child-led situational analyses, increasing participants' awareness and understanding - identifying hazards and 
developing solutions that meet children's own needs.

As researchers, our aim was to better understand the processes through which knowledge of risk is accumulated, translated and risk concepts are then developed and articulated to others.

Generating such understanding was aimed at improving the understanding of our partner nongovernmental organisations (NGOs) in their efforts to support children as risk communicators and actors, and to generate an empirical evidence-base for wider policy and programming influence. As researchers, therefore, we were already to some extent 'in sympathy' with the child-centred approach of our NGO partners and the child actors themselves. This reflects the normative agenda of PAR as an effort to improve development practice as well as the ethical basis for research (Wheeler; and Harvey, Burns and Oswald, this IDS Bulletin).

Our approach to PAR is centred on developing research processes that make room for reflection of existing knowledge and practice in order to help children consolidate knowledge and understanding within their groups, build confidence in their ability to act, reinforce selfbelief, and strengthen their capacity for further action on climate change adaptation and disaster risk management. In addition, recognising a child's right to participate, through engaging them in research, is regarded as crucial in empowering them as individuals and members of civil society. This helps develop their agency and confidence to exercise their citizenship rights and to influence the actions and decisions that affect their lives.

\section{Lessons from disaster management and climate change adaptation \\ 3.1 The research case studies}

The participatory action research presented here sought to understand how children in developing countries can take action within their communities to prevent disasters and adapt to climate change. With support from the UK Economic and Social Research Council (ESRC) and Plan UK, we worked with child-led development projects being implemented by the NGO Plan International through its country offices in El Salvador and the Philippines. These two countries are among the most disaster-prone in the world, with hazard burdens in many areas compounded by a high incidence of poverty and dependence on climate-sensitive natural resources. Plan's disaster risk reduction (DRR) programme was created as a result of both experiences of disaster impacts on children and communities, and the belief in the potential for child-led initiatives demonstrated by children's groups in these areas. The central actors in the research process were children and children's groups from 20 case study communities in El Salvador and the Philippines, although the research process also worked with adults in communities and in related institutions.

\subsection{Partner engagement, research ethics and methodological approach}

It is commonly acknowledged that research with children requires careful and sensitive methodological design (Morrow and Richards 1996). The research linked with ongoing development projects to investigate how children perceive risks, how they communicate these risks to others and how they turn knowledge into action. Children's groups were actively engaged with the research process, including reflecting on design, methods, results, and analysis. The research aimed to both foster and study the dynamics of children's participation in community development activities for risk reduction.

In linking with ongoing Plan projects, the research process was able to provide an avenue for reflection and learning in both the communities and in the national and international offices of Plan. This was achieved by regular debriefing and reflection sessions in the field, at field offices and national headquarters, and by requesting short written reflections from Plan staff. In engaging with an NGO, the action research interrelated its research process with development practice, promoting reflection and learning while providing the forum to challenge the prevailing project delivery modalities and tools. By doing so, the project was able to simultaneously learn from and inform the policy and practice of Plan International and its country programmes, both in framing its overall response to climate change and disasters around child agency and in improving community-based, child-led disaster risk reduction responses.

As we were working with children as our target community research ethics were a central 
consideration, particularly regarding processes for informed consent and child protection (Morrow and Richards 1996; Mahon et al. 1996). All researchers undertook Criminal Records Bureau checks or national equivalents and signed the Plan International Child Protection Policy. Specific research precautions included:

- Working at all times with Plan field staff, requesting consent from community leaders, teachers, parents and children themselves in advance of the presence of researchers and planned workshops or interviews.

- Informed consent procedures with all research participants through upfront statements of the purpose, methods and possible uses of research outputs, both to parents as part of permissions, and to children. This also clarified the independence and impartiality of researchers, confidentiality and anonymity of information, and participants' right to opt out of any activities.

- Sensitivity of research methods to ensure inclusion of different age groups and genders.

- At no time were researchers alone with a child or a group of children; a parent, Plan staff member or another researcher was always present.

- Providing feedback reports to communities.

The emphasis on ethics in research with children is unsurprising given the need to manage child protection issues and power imbalances. However, ethics can dominate methodological considerations and as a result:

Many other research issues are often disregarded and not given further attention since they are considered to be the same as those with adults. These include developing rapport; not imposing the researcher's own views and interpretations; validity and reliability; bearing in mind the research context; and clarity of questions (Punch 2002: 323).

Samantha Punch (2002) has noted that approaches to research with children have been seen from two extremes of either treating children as the same as adults or radically different to adults. Our research approach bridged these extremes, perceiving children as similar to adults but possessing different competencies (James et al. 1998). As such, methods were based on children's skills and our overall aim in working with children was to create a relaxed, fun atmosphere to allow the youth groups to take control of the research process, direction, and design. We attempted not to impose strong adult influences and to ensure that there was a strong motivation for engagement for all participants. This was reflected upon by a staff member of Plan Philippines:

Cultural sensitivity and adaptation [of methods] has been observed in the process with the emphasis on the open consultation with both the adult and the children... Children's perception on risks or hazards are really coming from their own experiences rather than a spoon-feed process where children are led to understand something that are new in their mindsets.

Working alongside Plan staff members, who have a long-term engagement in the case study communities, provided a safe space within which to build a greater rapport with the children and which ensured the longer-term sustainability of the action research process. Our engagement with community partners in the study communities helped to minimise the risk of psychological distress, particularly for child groups in their consideration of the impacts of climate change and disaster events. It also provided space for continued discussion and support for action after researchers have left. Embedding PAR into ongoing programmes enabled the local Community Development Facilitators to build on the learning and reflection with researchers and facilitate action on climate and disasters that was informed by the research sessions, as well as the more formal analysis.

During separate small-scale workshops with both adults and children, participants were engaged in a variety of oral, written and visual methods to express their perceptions, experiences and ideas concerning aspects of risk (hazards, vulnerabilities and capacities), risk management activities, and risk communication. Activities and results were split by gender and age where possible and frequent 'ice-breaker' games were facilitated in between activities. Rather than being explicitly part of a process of engaging children in reflection and analysis, these games were designed primarily to keep the groups energetic, develop confidence, and to introduce the tools and methods. Despite this, some games were also used as part of the research methodology. In El Salvador, the icebreaker of 
Table 1 Methods employed for child-centred PAR on disaster and climate change

\begin{tabular}{|c|c|c|c|}
\hline $\begin{array}{l}\text { Methods } \\
\text { *discussed in this article }\end{array}$ & $\begin{array}{l}\text { Child appropriate } \\
\text { (from } 9 \text { upwards) }\end{array}$ & $\begin{array}{l}\text { Youth appropriate } \\
\text { (from } 13 \text { plus) }\end{array}$ & Adult \\
\hline The King/Queen says* & $x$ & $x$ & \\
\hline Timeline & & & $x$ \\
\hline Seasonal Calendar & & $X$ for school & $x$ \\
\hline Past/Present/Future (drawings) & $x$ & $x$ & \\
\hline Benefits Race* & & $x$ & \\
\hline Act-a-Scene & $x$ & $x$ & \\
\hline We/Me map* & $x$ & $x$ & \\
\hline Stakeholder Mapping (modified) & & $x$ & $x$ \\
\hline Hazard Maps & & $x$ & $x$ \\
\hline Hazard Transect & $x$ & $x$ & \\
\hline Hazard Ranking and DRR Capacity & & $x$ & $x$ \\
\hline Hazard Grid (impact/frequency) & & $x$ & $x$ \\
\hline \multicolumn{4}{|l|}{ Community Visions (drawing)* } \\
\hline Message Flows & $x$ & $x$ & \\
\hline Show me Why (motivational drawings) & $x$ & $x$ & \\
\hline Participatory Video and Advocacy & & $x$ & $x$ \\
\hline Risk Management Pyramids* & & $x$ & $x$ \\
\hline
\end{tabular}

'The King/Queen Says' involved one participant acting as monarch and asking the room to divide as quickly as possible into different groupings of their choosing. By ensuring the inclusion of particular categories during their own turns as monarch, researchers were able to tally for example the gender, age and geographical locations of participants through an informal exercise. Although good practice for any type of PAR, making the process fun, engaging and rewarding was critical for retaining child participants who were there of their own free will. This was even more pertinent as the research activities were timed to take place on the weekend so as not to interfere with school work.

Learning from the practice commonly employed in focus group methodologies (Krueger 1988), three or more sessions with each group were planned in order to build trust with the researchers and gain confidence in the process. Researchers made at least two multi-day field visits per community which allowed them to reflect back to children what they had both heard - for validation by the children - and what they had learnt from the children. It also created the opportunity for the children to review critically their own knowledge and co-create findings. Initial analysis was co-created to inform the generation of easy-to-understand visual summaries such as matrices, flow charts, and diagrams. These were used to summarise findings and indicate relationships and interactions, which then provided stimulus to deeper group discussion by child groups (see below). This process of acting, learning, reflecting, consolidating knowledge, learning, acting again and so on, closely represents an iterative approach that is informed by not only the idea of reflective learning, but also that of praxis, in which action is framed by a belief in enhancing human wellbeing and respect for others.

\subsection{Experiences with tools for PAR with children}

Our research methods were based on established activities for vulnerability and capacity assessment, centred on participatory activities designed explicitly to facilitate community participation (O’Kane 2000; Veale 2005). These included tools such as: 
- Hazard identification

- Ranking grids

- Mapping vulnerabilities and capacities in the community

- Stakeholder analysis and mapping

- Group timelines

- Seasonal calendars

- Guided walks.

However, initial field testing found that they often had to be adapted to make them more childfriendly (Molina et al. 2009). For example, in the Camotes Islands of the Philippines, children had difficulties in understanding the linked concepts of 'stakeholder', 'power' and 'involvement' when asked to do a mapping exercise based on creating a Venn diagram of the relationships. This led to researchers introducing a 'We/Me map' to identify first the different kinds of people that children interacted with in different spaces such as the home/neighbourhood, the school, the community and beyond (i.e. stakeholders) and developing a revised step-by-step approach to mapping the levels of power and involvement with each of the stakeholders (see Molina et al. 2009). Whilst the data was of high value for the researchers, it provided a resource with which to develop further action later in the process when reviewing the target audiences for risk communication. Table 1 presents some of the methods employed during our action research process.

As noted earlier, keeping children energised and engaged was critical for the process; in the Philippines an activity labelled 'Benefits Races' split small groups of older children into equal teams, challenging them to rapidly identify the positive impacts of their top two risk-reducing activities (previously identified through a sharing of practice) through a race. Using a pen as a baton the team members each ran to the board and added a positive impact of the activity before returning to the team and passing the baton to the next member. Whilst feedback suggested this was among the favourites of the activities because it was exciting and lively - care was taken to ensure that the spirit of the activity remained fun and it was not used with younger children to avoid generating undue stress for participants. Although fun, it also acted to consolidate existing knowledge within the group, reinforcing their own sense of self-worth and achievement through the contributions they make to their communities when undertaking such activities. The 'data' from these sessions was later fed into other activities and eventually re-presented to the children to explore a more structured process for articulating and communicating risk during the second visit.

Using the 'benefits' identified in the race as a stimulus, children were asked to draw their vision of their community's future and their own lives after they have successfully delivered the DRR activities that they were already involved in. The envisioning activity aimed to highlight messages that children either did already convey, or felt were important to convey, in order to enable adaptation and risk reduction actions. The drawing engaged all ages of children and helped to stimulate creative thinking about what they are trying to achieve; as well as then allowing them to reflect on why they think such achievements are important/desirable and what else they could be doing to help them deliver their future community.

As a risk communication research programme, the drawing particularly supported the older participants to identify the specific messages they wanted to convey and to whom they should be targeted. In many cases the target audiences identified included existing stakeholders that they were already interacting with (from the We/Me map) but often embraced a much larger range of actors both within the community and at the national level who they felt could - or should - provide them with support to achieve their visions (including the President!). Whilst the process provided a dense set of qualitative data for researchers on both messaging, audiences and communication modes and media, it also provided a basis from which children could begin to expand their dialogue with different groups within their communities and to begin being proactive in reaching actors beyond those whom they usually dealt with. The participatory process revealed to them a wider domain within which they felt empowered to act.

\subsection{The two-trip approach: knowledge validation}

Ensuring that each community was visited at least twice was a critical and influential part of the process, both for the researchers and for the participants. To validate the risk communication elements of the research, the researchers were able to draw together the information from a series of activities conducted in phase one and 


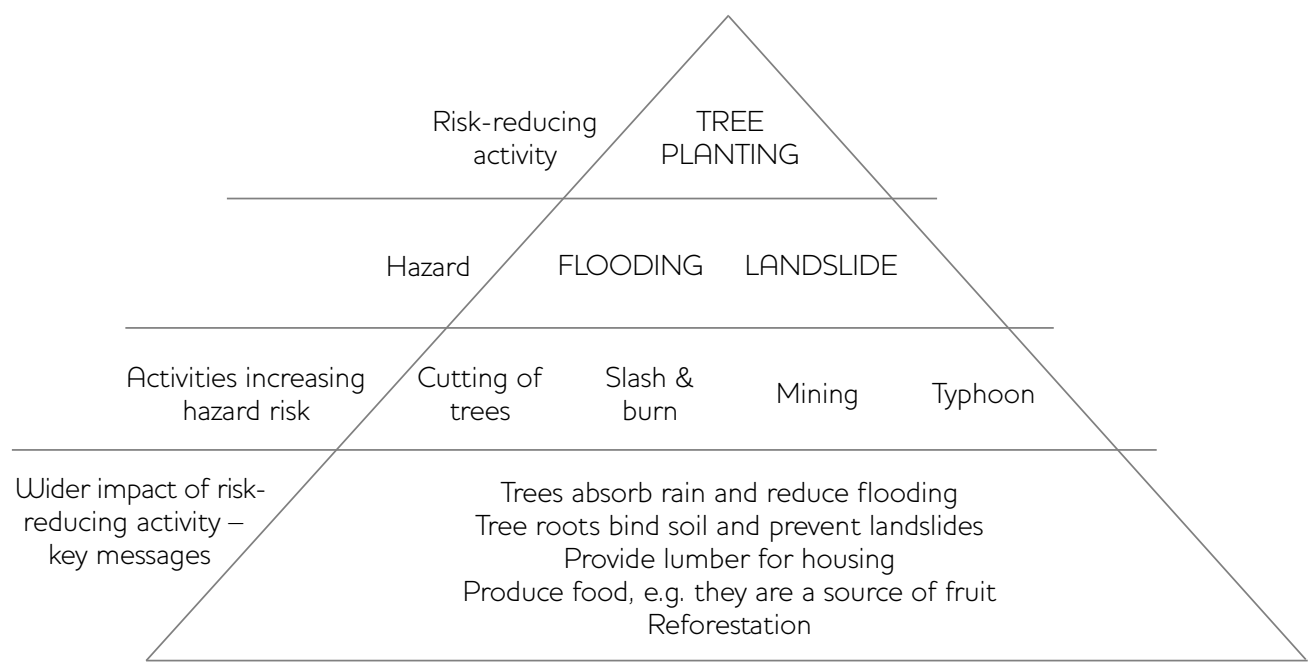

present it back to the children for validation. For example, producing 'pyramids' focusing on the children's key risk management activity (see Figure 1 for Tree Planting example) and linking it with the messages from the Benefits Race/ Community Visioning and the hazards identified in the Hazard Ranking and Hazard Grids. ${ }^{1}$

Re-presenting the data in this way not only allowed the children to validate and add to or amend the content - thereby avoiding the bias of external reproduction - but it also created new spaces to discuss the linkages between their knowledge on the benefits of their risk-reducing activities, with the hazards that they were trying to reduce, and support them to move forward and explore more clearly how to align different and specific messages to particular actors.

... children in Catig, Lilo-an, Southern Leyte recognised that their coastal clean-up activities were aimed at increasing the fish population and improving livelihood sustainability (message for fisherfolk associations and to obtain local government support) but required everyone in the community to participate in proper waste management and segregation activities (message for family and the village council) (Molina et al. 2009).

As well as providing further support for children to identify ways to realise their role as change agents, another outcome of the two-trip approach was the preliminary analysis of data from first phase visits to draw out factors that appeared to enable or limit the children's capacity to act. During the follow-up visits children were invited to arrange the set of factors from the most significant to the least. However, they were given the freedom to remove factors which were not relevant to their context and add those which were not included. This allowed children to see which issues they may need to address as well as what resources they need to strengthen their ability to undertake development-oriented initiatives, including disaster risk reduction. In many of the Filipino groups, for example, they planned to address some of the issues that limit their participation such as lack of finance, lack of confidence, and a lack of adult understanding of their goals. In El Salvador, this reanalysis was integrated with presentation by children's groups of results and activities to other members of the community.

The second phase of research also included reflective spaces for children to analyse the differences between results of hazard ranking and identification exercises carried out in groups separated by age (adult, youth and children) and gender (men and women, boys and girls). By preparing colour-key matrices that showed the results of the hazard identification and ranking processes according to such separation, the difference in the hazard perceptions between children and adults, men and women, boys and girls could be seen. Children were invited to 
consider the reasons for differences and to review the implications of such differences for communications. This was geared to shaping specific messages for different adult audiences in relation to their suggested strategies for risk management. The use of such tools helps to foster a two-way learning for the researchers and young people in the field of DRR and adaptation. The participatory and interactive nature allows each participant to share his or her thoughts, and at the same time gain awareness from others' experiences and insights. It also provides space to explore further opportunities to continuously strengthen and sustain efforts to improve safety, sustainability, and community resilience.

Whilst the information and analyses are seen as directly relevant and useful for supporting the children to move forward, feeding this information back to the NGO partner also stimulated reviews of their disasters and risk management activities. For example, the research revealed a narrow set of perceived stakeholders at the community level with whom the children interacted, and the children seemed unaware of specific groups, such as fishing or farming cooperatives with whom they could build alliances. It also revealed a gap between the approach to learning through the much anticipated and enjoyable summer training camps and the weak impact of the learning on community activities. For Plan Philippines, the research was timely, as it came as DRR was shifting from a 'project' for the country-office to become a cross-cutting theme, thus they were keen to learn about the linkages with their existing programme areas, particularly in relation to gender. The production of the hazard matrices according to age and gender helped to identify clear links to other programme areas, in particular with health and WASH programmes. In El Salvador, the research process helped to refocus the disasters and risk management programming around the wider community and external agents rather than predominantly centring on children's groups.

\subsection{Beyond empowerment - magnifying voice and impact}

The PAR methods and principles described in this article reflect the Kindon et al. (2007) description noted earlier; seeking to support and improve children's agency for action through engagement in the research process. However, the normative belief that the poor will 'progressively transform their environment' (Rahman 1993: 68) is a particular challenge in the context of marginalised groups, including children, thus putting a greater emphasis on others 'play[ing] a catalytic or supportive role' in the wider environment. The PAR process in $\mathrm{El}$ Salvador and the Philippines revealed that children's ability to exercise their rights and agency is often constrained by culturally embedded social practice and behavioural norms that do not recognise children as actors or independent agencies in the community - or even the household. To create an enabling policy environment that supports and enables childcentred DRR or climate change adaptation requires different types of action and responses across scales. Working towards child-centred DRR also needs to focus on influencing policy at international, national and sub-national levels, as well as training and capacity-building with DRR actors to take children's needs and capacities into account (see Seballos and Tanner 2011). Change at the local level without intervention or shifts at the higher scales are more likely to be incremental and small-scale changes - those in positions of power and influence must be willing and able to engage and work with children in both policy development and programme implementation.

Strong empirical research has a role to play in providing an evidence base for advocacy in different spheres. Researchers involved in these cases have been able to share the learning from and with children in a range of international spaces - indirectly increasing the returns to the children. But to be truly transformative in supporting children to learn and benefit from the PAR process, they should also be partners in disseminating its results and presenting their knowledge - ultimately it is children's views that must be heard in the adult decision-making arena. Through the established partnership with Plan International - who offer expertise in facilitating children's participation in global spaces (see Walden et al. 2009), the researchers have been privileged to be part of a process to create safe spaces for dialogue between children and adults at the global level.

\section{Limitations of PAR for children and disasters}

Assessing the limitations of the PAR approach in this case is centred on the type of PAR that was 
followed. Carr and Kemmis (1986) distinguish three models of PAR that range from technical (led by the external researcher in order to test a preconceived theory or improve a product), practical (in which participants work with researchers to analyse and interpret results on an equal basis), through to emancipatory (in which relationships are equal and theories may be brought by both participants and researchers). This research stopped well short of being emancipatory, with the research framework and design at least initially developed by the external researchers. Whilst participatory methods were employed, and much of the results and analysis was retained by the groups for later use in developing risk management responses, others remained more extractive, with a focus on enabling researchers to cross-compare findings between case study locations and countries.

Nevertheless, in engaging children in a process of knowledge generation and analysis, the research attempted to break down some of the assumed hierarchies between researchers and researched that are common to orthodox approaches (FalsBorda and Rahman 1991). At the same time, in working with participants to find practical solutions to challenge root causes of disaster vulnerability, the research was characterised by an adherence to the transformative rather than extractive tenets of action research (Hickey and Mohan 2005). These are underpinned by Paolo Freire's (1976) concept of problematisation, analysis of lived experience through which people are able to challenge oppressive phenomena which may be taken as given and which they may unknowingly reproduce.

One of the key methodological consequences of this was the need to manage the ethical dimensions of risks and conflicts that emerged by challenging existing power relations and vested interests in disaster risk management responses by children and community groups. This was revealed in a case where the key risk-reducing activity identified by the children was linked to a critical income source for one community in the Philippines. Small-scale mining was seen to be creating skin diseases and reduced fish populations (impacting food and income security) due to water pollution and increasing run-off and localised flooding due to loss of vegetation. Children were particularly affected by the skin diseases as they played, bathed and washed laundry in the river. By focusing on the risk perceptions of the children, their risk management activities and their rights as actors in the community, the PAR process held the potential to challenge the power of the adults in the community, by privileging the knowledge of the children and contesting spaces that constrained their agency.

The research process revealed that the children's group had undertaken an awareness-raising campaign against the mining. This included a house-to-house collection of signatures for a petition to the local and provincial government, a process which had been stopped by elders in the community. Many of the community, including parents of those children involved and even some of the children themselves, were employed by the small-scale mining business, bringing home much needed income to support their families. The research project reopened the space to challenge this constraint to children's agency and the contentious issue it represented. Working through Plan's longer term programmes of engagement in the community, the issue was followed up through a spin-off project. This project employed participatory video techniques to create advocacy pieces that were screened at community and regional scales to stimulate debate about the pros and cons of this livelihood activity. ${ }^{2}$ These videos allowed children's voices to be heard in spaces beyond their own community, where many of the decisions driving mining activity are made.

Similarly, in El Salvador, the researchers and NGO partners had to remain aware of the potential that the risk reduction activities identified by the children's groups assessment part of the PAR process may themselves put the children at risk of harm (Mitchell et al. 2009). The children of the Petapa Emergency Committee identified the unregulated extraction of rocks and stones from the river as a major risk factor leading to increased erosion and vulnerability to flooding of houses near the river. Signs prohibiting extraction for personal use have since been erected with the agreement of the local leaders. Children recounted the story of the arrival of a lorry from outside the community to load stones from the river. Acting on the strength of their convictions a number of children went to the river to protest at this activity, sitting on top of the lorry until it agreed to leave. Although for personal use, this 
collection had apparently been sanctioned by local authorities, revealing power relations central to the challenge of risk reduction.

Empowerment of children's agency through PAR may therefore lead to children's groups directly challenging vested interests and power relations that adversely affect vulnerability. These challenges, including direct action as seen in Petapa may inadvertently put children in positions of potential danger. Such possibilities need to be carefully monitored by facilitating agencies, which may be in a strong position to mediate in such situations and ensure that action does not put children at risk unacceptably. The research project was therefore reliant on the continuity of engagement provided by Plan Philippines in order to ensure that this debate challenged power relations without putting the children themselves at risk of harm.

Finally, the research also demonstrated the challenge of inclusive processes in PAR: Who participates and who doesn't, who speaks and whose voice is dominant in the process? In the case of this research the challenge of inclusion became clear after the first phase of field visits. Participatory activities and household interviews revealed that the interaction of children with others who engaged in community activities or public service, particularly parents and older relatives, was a strong influence on their participation in community programmes. Through partnering an active NGO, researchers were working exclusively with existing formalised groups, the issue of who did not participate became a clear challenge to the research.

Researchers and Plan staff in both countries reflected on the fact that children's groups did not include all children in the community, neither those attending school, or those where numbers of 'out of school youth' existed. In reality the children's groups often included college students who 'no longer went to school', whilst excluding those out of school for socioeconomic or cultural reasons. This frustrated the capturing of knowledge, communication methods and agency of locally excluded groups within the larger excluded category of 'children'. In the second phase of field visits, local leaders in select communities facilitated short sessions with those children who were not part of the Plan organised groups, focusing on their own risk identification and specific responses to such risks.

\section{A normative framework for PAR on children and disasters}

By way of conclusion, we suggest that that a child-friendly cooperative enquiry model for research on climate change and disasters should be underpinned by the following principles.

Relevance. Group engagement must be facilitated in a manner that children can relate to and becomes meaningful for them. The outcomes of their participation in the research process and the ways in which this can support and enhance their existing practices must be clear to them and any of the supporting actors involved, allowing them the space in which to shape the process to further provide support where they feel it is most relevant. In doing so, methods should be informed by the cultural norms and the age range of participants.

Creativity. Research methods are focused on generating a lively and fun environment within which the research can be conducted. Creative methods keep children motivated, supporting them to communicate freely on issues that are important to them. A mix of oral, visual, and written activities help children to express their perceptions, experiences, and ideas concerning hazards, vulnerabilities, and capacities in whichever form they feel most comfortable with. In addition, regular ice-breakers help to break up sessions and burn off energy as well as building rapport with other participants and the researchers. These methods may simply be a functional way of engaging children rather than part of a transformative agenda that harnesses their particular ways of knowing.

Participation. To engender participation from a broad age range, age-appropriate activities should be carried out in small groups. In this way, individual children are encouraged to feel confident enough to participate and are not overwhelmed by demanding methods. It is important that methods are iterative, allowing children themselves to shape and change the research process in response to emerging insights. Feedback from children on both knowledge generated and the approaches used by researchers is important for enhancing both empowerment and ownership of the outputs. 
Flexibility. It is important that the methods and processes are responsive to children's needs and interests. Researcher intervention should be limited, to the extent possible, to an explanation of the tool or method. They should then create the opportunity for children to engage with the processes in an open manner, taking methods forward in ways that support their own learning and reflection, as well as their cultural norms.

Sustainability. Immediate relevance to the participants should be a core concern and children should gain from the experience of

\section{Notes}

* The research described in this article was carried out with financial support from the Economic and Social Research Council under the ESRC First Grants Programme (grant no. RES- 061-25-0148) and Plan UK. The authors are indebted to the support of Plan staff in the UK, El Salvador and the Philippines, particularly Kelly Hawrylyshyn, Nick Hall, Mercedes Garcia and Baltz Tribunalo, as well to research partners in both countries for

\section{References}

Back, E.; Cameron, C. and Tanner, T.M. (2009) Children and Disaster Risk Reduction: Taking Stock and Moving Forward, Research Report, Children in a Changing Climate, Brighton: IDS

Balaban, V. (2006) 'Psychological Assessment of Children in Disasters and Emergencies', Disasters 30: 178-98

Bangay, C. and Blum, N. (2010) 'Education Responses to Climate Change and Quality: Two Parts of the Same Agenda?', International Journal of Educational Development 20: 359-68

Bunyavanich, S.; Landrigan, C.P.; McMichael, A.J. and Epstein, P.R. (2003) 'The Impact of Climate Change on Child Health', Ambulatory Pediatrics 3: 44-52

Carr, W. and Kemmis, S. (1986) Becoming Critical: Education, Knowledge and Action Research, London: Falmer Press

Chambers, R. (2000) Whose Reality Counts?, Rugby: Intermediate Technology Development Group Publishing del Ninno, G. and Lindberg, M. (2005) 'Treading Water: The Long-term Impact of the 1998 Flood on Nutrition in Bangladesh', Economics and Human Biology 3: 67-96

Fals-Borda, O. and Rahman, M.A. (eds) (1991) Action and Knowledge: Breaking the Monopoly with participating in the research. However, it is essential that the empowerment and learning gathered through the participation can be put into action within a supportive structure. The process of co-production of knowledge that builds awareness and agency needs to be channelled into enabling environments that support the participants' ability to put new knowledge and improved strategies into action. Without followup and spaces within which to further develop learning and action, the broader outcomes of a process of co-production of knowledge and learning becomes redundant.

making this research possible. We extend a very large thank you to all the children and families who gave their time voluntarily to participate in the research process.

1 The activities increasing the hazard risks were identified by children as hazards in the ranking and grid exercises, as well as the specific hazards themselves.

2 Watch the video at: http://tinyurl.com/miningpv.

Participatory Action-Research, New York: Apex Press

Freire, P. (1976) Education, the Practice of Freedom, London: Writers and Readers Publishing Cooperative

Harcourt, D.; Perry, B. and Waller, T. (2011) Researching Young Children's Perspectives, Abingdon: Routledge

Hickey, S. and Mohan, G. (2005) Participation: From Tyranny to Transformation? Exploring New Approaches to Participation in Development, London: Zed Books

Ince, A. (2008) Book review: Kindon et al. (2007) Participatory Action Research Approaches and Methods, RGS-IBG Urban Geography Research Group Book Review Series, http://urbangeography.org.uk/book-reviews (accessed 9 January 2012)

James, A.; Jenks, C. and Prout, A. (1998) Theorizing Childhood, Cambridge: Polity Press

Kemmis, S. and McTaggart, R. (eds) (1988) The Action Research Planner, Victoria, Australia: Deakin University

Kindon, S.; Pain, R. and Kesby, M. (2007) Participatory Action Research Approaches and Methods: Connecting People, Participation and Place, London and New York: Routledge 
Krueger, R.A. (1988) Focus Groups: A Practical Guide for Applied Research, Newbury Park CA: Sage

Lauten, A.W. and Lietz K. (2008) 'A Look at the Standards Gap: Comparing Child Protection Responses in the Aftermath of Hurricane Katrina and the Indian Ocean Tsunami', Children, Youth and Environments 18: 158-201

Maguire, P. (2001) 'Uneven Ground: Feminisms and Action Research', in Peter Reason and Hilary Bradbury (eds), The Sage Handbook of Action Research: Participative Inquiry and Practice, London: Sage: 59-69

Mahon, A.; Glendinning, C.; Glarke, K. and Craig G. (1996) 'Researching Children: Methods and Ethics', Children and Society 10: 145-54

McIntyre, A. (2008) Participatory Action Research Handbook, Thousand Oaks CA: Sage

McTaggart, R. (ed.) (1997) Participatory Action Research: International Contexts and Consequences, Albany NY: State University of New York Press

Minkler, M. and Wallerstein, N. (eds) (2003) Community-based Participatory Research for Health, San Francisco: Jossey-Bass

Mitchell, T.; Tanner, T.M. and Haynes, K. (2009) Children as Agents of Change for Disaster Risk Reduction: Lessons from El Salvador and the Philippines, Children in a Changing Climate Working Paper 1, Brighton: IDS

Mitchell, T.; Haynes, K.; Hall, N.; Choong, W. and Oven, K. (2008) 'The Role of Children and Youth in Communicating Disaster Risk', Children, Youth and Environments 18: 254-79

Molina, G.; Molina, F.; Tanner, T.M. and Seballos, F. (2009) 'Child-friendly Participatory Research Techniques for Community-based Adaptation and Disaster Risk Reduction', Participatory Learning and Action 60: 160-6

Morrow, V. and Richards, M. (1996) 'The Ethics of Social Research with Children: An Overview', Children and Society 10: 90-105

Nieuwenhuys, O. (1997) 'Spaces for the Children of the Urban Poor: Experiences with Participatory Action Research (PAR)', Environment and Urbanization, April 9.1: 233-50

O'Kane, C. (2000) 'The Development of Participatory Techniques: Facilitating Children's Views about Decisions which Affect Them', in P. Christensen and A. James (eds), Research with Children: Perspectives and Practices, London: Falmer Press: 136-59

Peek, L. (2008) 'Children and Disasters: Understanding Vulnerability, Developing
Capacities and Promoting Resilience - An Introduction', Children, Youth and Environments 18: $1-29$

Punch S. (2002) 'Research with Children: The Same or Different from Research with Adults?', Childhood 9: 321-41

Rahman, M.A. (1993) People's Self-development, Perspectives on Participatory Action Research, a Journey through Experience, London: Zed Books

Reason, P. and Bradbury, H. (eds) (2001) The Sage Handbook of Action Research: Participative Inquiry and Practice, London: Sage

Schrader, A.M. (2007) 'Learning at the Edges: Participatory Action Research and Child Maltreatment in Post-War Guatemala', Bulletin of Latin American Research 26.4: 516-32

Seballos, F. and Tanner, T.M. (2011) Enabling Child-Centred Agency in Disaster Risk Reduction, background paper, UNISDR Global Assessment Report (GAR) 2011, Geneva: United Nations International Strategy for Disaster Reduction (UNISDR)

Tanner, T.M. (2010) 'Shifting the Narrative: Child-led Responses to Climate Change and Disasters in El Salvador and the Philippines', Children and Society 24: 339-51

Tanner, T.M.; Garcia, M.; Lazcano, J.; Molina, F.; Molina, G.; Rodríguez, G.; Tribunalo, B. and Seballos, F. (2009) 'Children's Participation in Community-based Disaster Risk Reduction and Adaptation to Climate Change', Participatory Learning and Action 60: 54-64

Veale, A. (2005) 'Creative Methodologies in Participatory Research with Children', in S. Greene and D. Hogan (eds), Researching Children's Experience, Thousand Oaks CA: Sage

Walden, D.; Hall, N. and Hawrylyshyn, K. (2009) 'Participation and Protection: Children's Involvement in Climate Change Debates', IDS In Focus 13.4, Brighton: IDS

Waterson, T. (2006) 'Climate Change - The Greatest Crisis for Children?', Journal of Tropical Pediatrics 52: 383-5

Weissbecker, I.; Sephton, S.E.; Martin, M.B. and Simpson, D.M. (2008) 'Psychological and Physiological Correlates of Stress in Children Exposed to Disaster: Review of Current Research and Recommendations for Intervention', Children, Youth and Environments 18: $30-70$

Wisner, B. (2006) Let Our Children Teach Us! A Review of the Role of Education and Knowledge in Disaster Risk Reduction, Bangalore: Books for Change 